\title{
A CAD Paradigm to Produce Zillij Style of Geometrical Patterns for Wooden Carvings
}

\author{
Vishal Gulati \\ GJ University of Science and \\ Technology, Hisar, India
}

\author{
Puneet Tandon \\ PDPM-Indian Institute of Information \\ Technology, Design and \\ Manufacturing, Jabalpur, India
}

\author{
Hari Singh \\ National Institute of Technology \\ Kurukshetra, India
}

\begin{abstract}
This work presents a CAD paradigm to produce traditional zillij style of geometrical patterns using ubiquitous polygonal technique. This method makes use of a grid generated from diagonals of $n$-sided regular polygon. The grids are in the form of a mesh of having large number of irregular polygons. The vertex of any irregular polygon in the grid is viewed as the point of intersection of two diagonals. These irregular polygons, when located in radial symmetry, generate a zillij style of pattern. The design possibilities increase by increasing the diagonals elements and endless variations of patterns on an isometric grid can be created. These geometrical patterns are ideally suited to computer-controlled manufacturing, so can be executed on a flat wooden surface to produce carvings.
\end{abstract}

\section{Keywords}

$\mathrm{CAD}$, Zillij patterns, Wooden carving, Polygonal technique

\section{INTRODUCTION}

Geometry is a predominant decorative theme in Islamic art, usually dominating other ornamental motifs. Throughout history, Islamic decorative art has focused on the depiction of geometrical patterns rather than on figures, because it is feared by Muslims that the depiction of the human form is idolatry and thereby a sin against Allah, forbidden in the Qur'an. Islamic art encompasses a great variety of geometric ornamental patterns in the different parts of the Muslim world. Zillij patterns' in Moroccan Arabic represents one of the world's greatest geometric ornamental design traditions. Since ancient times, zillij patterns have been used for decoration of buildings particularly tombs and mosques, carpets, fountains, and much more throughout Morocco. This form of patterns is drawn within the constraints of mathematical symmetry and the laws of proportion. The striking characteristic of zillij patterns is the prominence of stars and rosettes (Figure 1). In these patterns, the basic elements are simple shapes (polygons as shown in Figure 2), repeated in the patterns following bilateral or radial symmetry. Due to linear and repetitive character of geometric decoration, zillij patterns are widely being used in decoration industry, particularly in commercial applications such as apparel and interior designs. Moreover, the presence of great variety of geometrical motifs and the possibility of adapting for different materials (tile, plaster, brick and wood) have encouraged the use of zillij patterns in decoration.

It is not always easy to create contemporary art in decoration of the items like home furnishings, fabrics, carpets, glass panels, ceramic tiles, furniture etc. So, traditional styles can be employed as fundamental resources to archive decorative effects. The intention here is to understand traditional zillij style of the past and to innovate with new interpretations of old style and with new styles altogether.
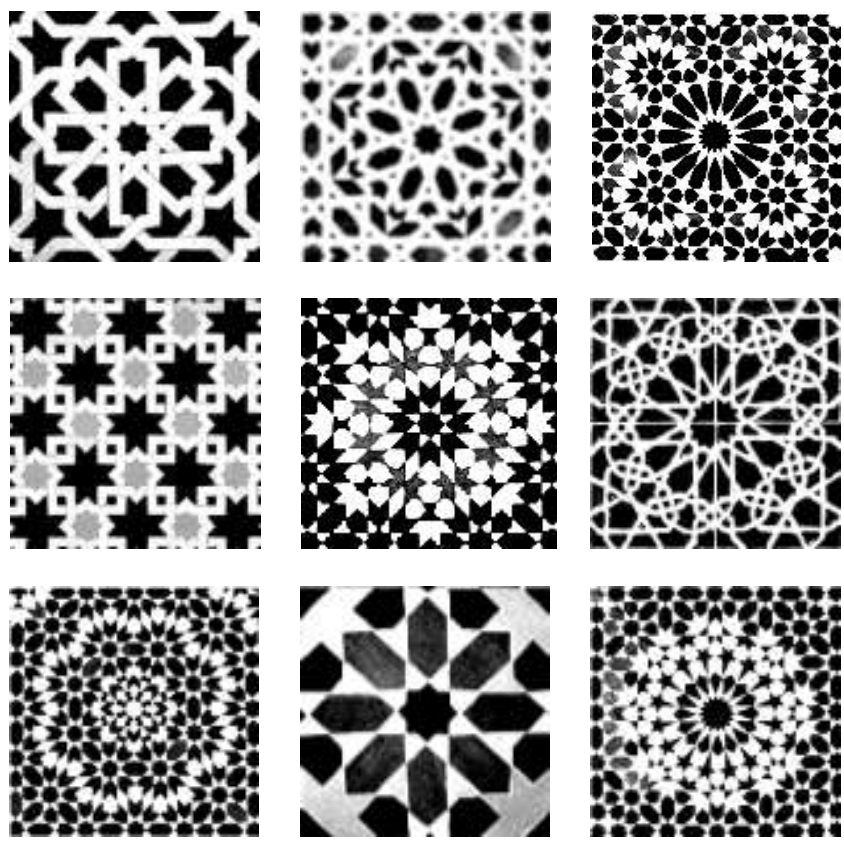

Figure 1: Zillij patterns [1-2]

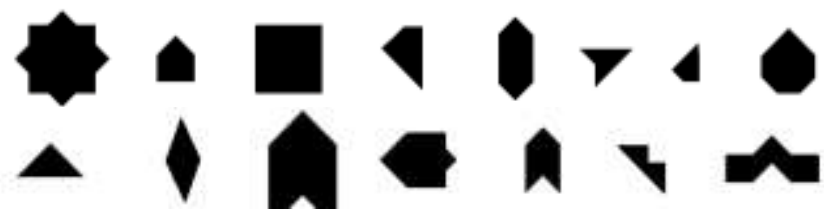

Figure 2: The basic elements in zillij patterns

This work presents a CAD paradigm to produce zillij style of geometrical patterns using ubiquitous polygonal technique. The rendered geometrical patterns are ideally suited to computercontrolled manufacturing for building real world artifacts. In order to produce a part of the human cultural heritage, this work is towards the decoration of wooden surface with computer generated zillij style of geometrical patterns. The decoration 
comprises wood carving with computer controlled laser cutting machine that would previously have only been possible for skilled craftsmen. Further, carved wooden surfaces can be fit in the furniture, window or door to produce a traditional piece of finished and distinguished work.

\section{LITERATURE REVIEW}

A considerable research into modeling of geometrical patterns has taken place. Abas discussed the evolution of classical geometric methods for Islamic geometrical patterns and developed algorithms based on group theory for efficient generation of all crystallographic repeat patterns using modern computer graphics [3]. Ostromoukhov presented mathematical tools for computer-generated ornamental Islamic patterns [4]. Kaplan presented a procedure for constructing Islamic star patterns based on placing radially-symmetric motifs in a formation dictated by a tiling of the plane, and showed some styles in which they can be rendered [5]. Aljamali described and demonstrated procedures for constructing Star/Rosette unit patterns based on the proposed classification in a grid formation dictated by the final design of the unit pattern [6]. Kaplan also presented a paradigm that makes the flexibility of NC machining available to the non-technical woodworker. He proposed a machine architecture and software tools of realizing art in wood. As a proof-of-concept of the new paradigm, he showed a prototype NC milling lathe, a design tool for the special case of Islamic star patterns, and a decorative piece designed and cut using the system [7]. Djibril proposed a new method for the indexing and classification of Islamic stars pattern images based on rotational symmetry information. He also proposed a computational model for the extraction of symmetry features of Islamic geometrical patterns' images using the discrete symmetry groups' theory [8]. His original approach was based on the extraction of symmetry information using a Quadtreebased Symmetry Transform (QST) [10]. Grunbaun derived a fundamental region by decomposing the star pattern by their symmetry groups [9]. Ilkturk attempted to combine mathematics and visual arts by utilizing Islamic geometric patterns [11]. Jowers explored the impact of emergence on a design space via consideration of different methods used to generate designs in a particular style. He investigated three distinct methods of generating Islamic geometric patterns and explored the extent to which emergence is employed in these methods [12].

\section{MODELING APPROACH}

A classical methodology known as the polygonal technique, has been employed to represent zillij style of geometrical patterns. This methodology makes use of grids generated from the diagonals of regular polygon. Figure 3 shows such a type of grids which are worked out to keep the pattern symmetrical and to maintain the visual balance. The grids are in the form of a mesh having a large number of irregular polygons. The patterns are created by selecting these irregular polygons in the grid. Design possibilities increase by increasing the diagonals; in fact, with increase in the number of sides of the regular polygon. The patterns derived from 6,8 and 10-sided polygonal grids are represented in Figure 4. These symmetrical patterns remain invariant under certain classes of transformations such as rotation, reflection, inversion, or more abstract operations. These rendered patterns are in the form of a star/rosette following radial symmetry.

The vertex $(\mathrm{i}=1,2,3 \ldots \mathrm{n})$ of an $\mathrm{n}$-sided regular polygon of size (r) is defined as:

$\left(\mathrm{x}_{\mathrm{i}}, \mathrm{y}_{\mathrm{i}}\right)=\left(\mathrm{r} \sin \theta_{i}, \mathrm{rcos} \theta_{i}\right)$ where $\theta_{\mathrm{i}}=2 \pi(\mathrm{i}-1) / \mathrm{i}$

A diagonal is a line segment connecting any two nonadjacent vertices (say p and q) of a regular polygon and its slope is represented as:

$\mathrm{m}_{\mathrm{p}-\mathrm{q}}=\left(\cos \theta_{q}-\cos \theta_{p}\right) /\left(\sin \theta_{q}-\sin \theta_{p}\right)$
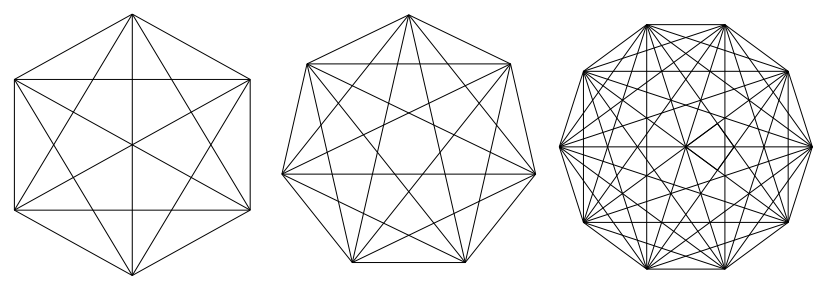

Figure 3: The grids generated from diagonals
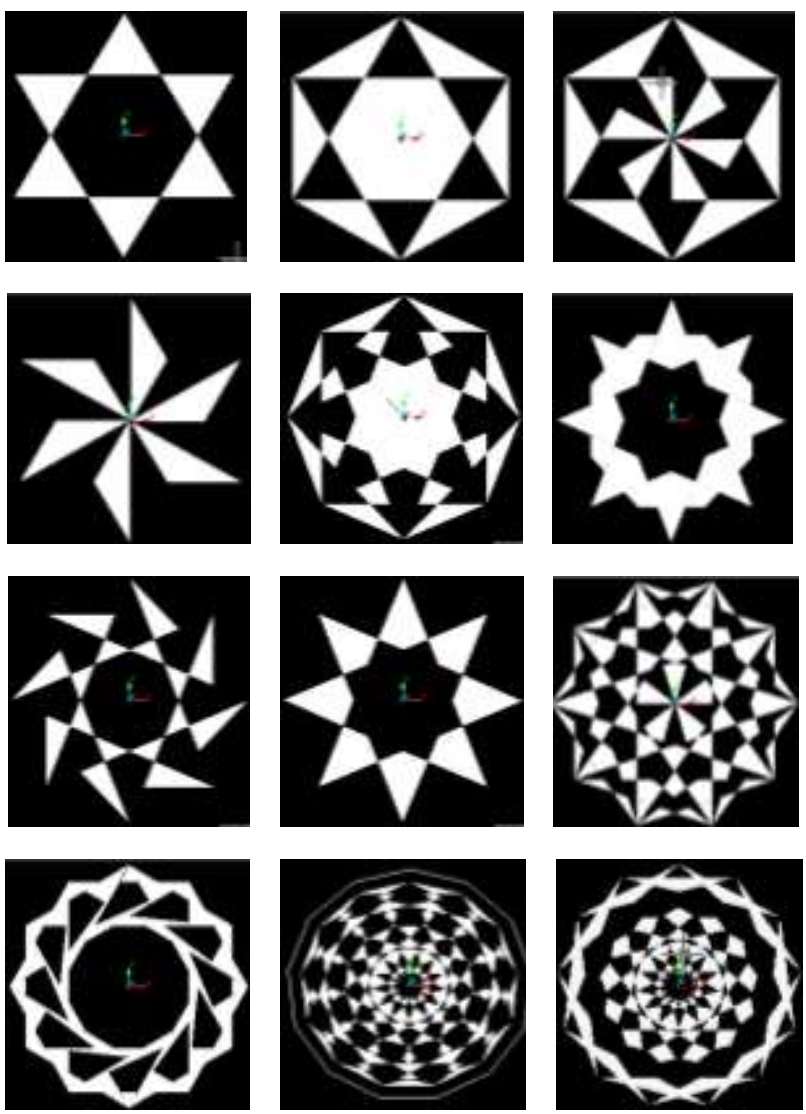

Figure 4: The rendered zillij style of patterns derived from 6, 8 and 10-sided polygonal grids

In the grid of diagonals, any vertex of the irregular polygons is viewed as a point of intersection (say k) of two diagonals (connecting two nonadjacent vertices $\mathrm{p}-\mathrm{q}$ and $\mathrm{a}-\mathrm{b}$ of the regular polygon). The coordinates of a vertex of the irregular polygon is represented as:

$\mathrm{X}_{\mathrm{k}}=\mathrm{r}\left(\mathrm{m}_{\mathrm{p}-\mathrm{q}} \sin \theta_{p}-\mathrm{m}_{\mathrm{a}-\mathrm{b}} \sin \theta_{a}+\cos \theta_{a}-\cos \theta_{p}\right) /\left(\mathrm{m}_{\mathrm{p}-\mathrm{q}}-\mathrm{m}_{\mathrm{a}-\mathrm{b}}\right.$ 
$\mathrm{Y}_{\mathrm{k}}=\mathrm{m}_{\mathrm{p}-\mathrm{q}}\left(\mathrm{X}_{\mathrm{k}}-\mathrm{r} \sin \theta_{p}\right)+\mathrm{r} \cos \theta_{p}$

From the above equations, it is revealed that coordinates a vertex of the irregular polygon are function of size (r) and vertex number (i), so considered as modeling parameters in the parameterized modeling of the patterns.

For an example, a grid shown in Figure 5 is worked out for modeling the patterns. The vertices of the regular polygon are numbered as $1,2,3 \ldots \mathrm{n}$. In order to select an irregular polygon $\mathrm{ABCD}$ in the grid, modeling parameters (vertex numbers) are identified for positioning the points (A, B, C, and D) which have been viewed as the points of intersection of two diagonals in the grid (Table 1). The zillij style of patterns represents a type of theme of recurring regions in a radial symmetry so that the rendered pattern looks the same after a certain amount of rotation. The selected region $\mathrm{ABCD}$ (Figure 6a) is regularly arranged around a central axis to form of a star/rosette pattern. The zillij style of patterns radiates from center to outward with no gaps and no overlaps. Further, the rendered star pattern is extended by selecting more regions in order to create another form of pattern (Figure 6b).

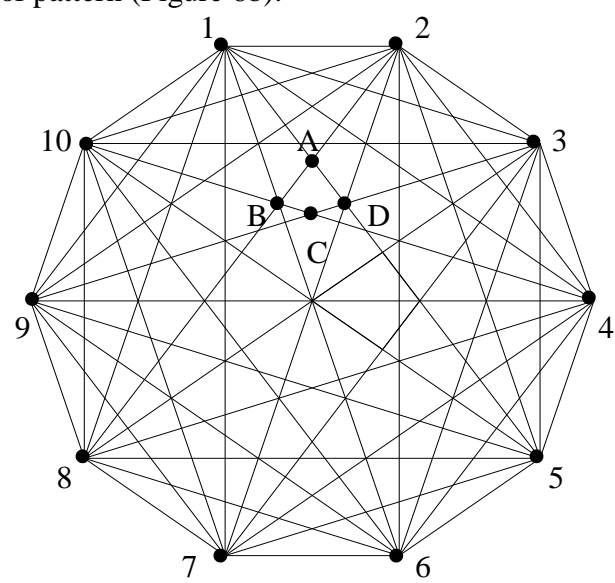

Figure 5: An irregular polygon $\mathrm{ABCD}$ in the grid

Table 1: Vertices defined with the points of intersection of two diagonals

\begin{tabular}{|l|c|c|c|c|}
\hline Point of intersection & A & B & C & D \\
\hline First diagonal (p-q) & $1-5$ & $2-8$ & $4-10$ & $3-9$ \\
\hline Second diagonal (a-b) & $2-8$ & $4-10$ & $3-9$ & $1-5$ \\
\hline
\end{tabular}

\section{IMPLEMENTATION}

This CAD paradigm is implemented under the ActiveX and Visual Basic Application (VBA) programming environment using AutoCAD. The combination of the powerful ActiveX Automation object model in AutoCAD and VBA presents a compiling framework for customizing the AutoCAD software program.

The design algorithm begins with mathematical description of the geometrical patterns using ubiquitous polygonal technique. Then, CAD programming interfaces are used to turn the mathematical descriptions of patterns into computer program. These programs render the patterns on the computer screen. The $\mathrm{CAD}$ data of these patterns can be transferred to a variety of computer-controlled machines.
A CNC machine with laser cutting tool is used for carving rendered geometrical patterns into wood. The laser uses a beam of light as the carving tool. The depth of cut produced by laser cutting depends greatly on the power of the light being focused through the laser lens.
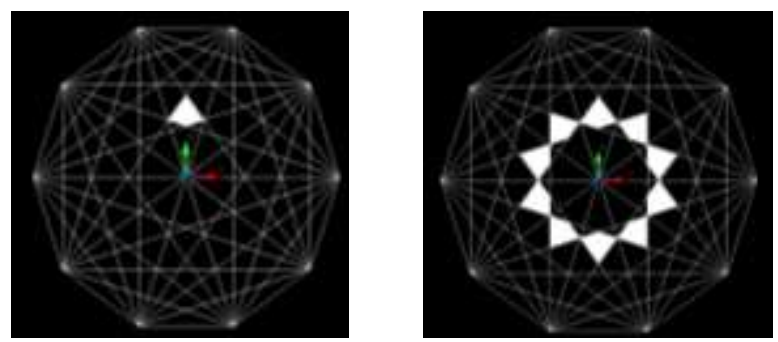

(a)
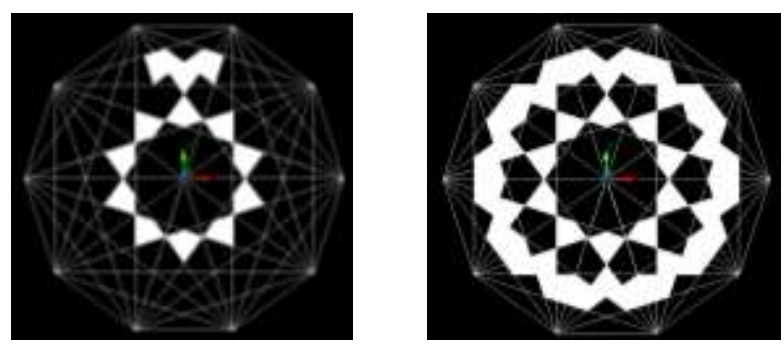

(b)

Figure 6: Rendered patterns

\section{CONCLUDING REMARKS}

In order to keep pace with continuous demand for novelty in ornamental patterns, the work is towards the generation of new geometrical patterns to apply for wood surface decoration. This paradigm provides the capability of generating a large number of variations in the traditional Zillij style of patterns. The proposed methodology builds up an ornamental product (wooden carving) in the integrated design and manufacturing environment. The rendered geometrical patterns provide precise information to guide the paths of cutting tool and are in harmony with computer controlled carving. Laser cutting has got the same pressure sensitivities as a chisel or knife. This allows us to carve patterns with laser cutter that would previously have only been possible for skilled craftsmen. One of the patterns carved on the laser cutter is shown in Figure 7. This pattern does not elaborate on laser cutting methodology but just presents a case study in the form of computer assisted manufacturing of a carved pattern.

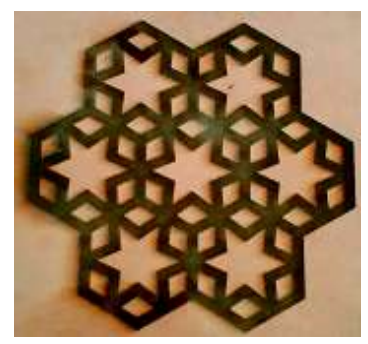

Figure 7: Carved pattern on the laser cutter 


\section{REFERENCES}

[1] Castera J. M., 1999, Decorative Art in Morocco, A. C. R. Edition.

[2] Zillij Patterns: http://www.Crayola.com.

[3] Abas S. J. and Salman A. S., 1992, Geometric and GroupTheoretic Methods for Computer Graphics Studies of Islamic Symmetric Patterns, Computer Graphics Forum, Vol. 1, No. 1, pp. 43-53.

[4] Ostromoukhov V., 1998, Mathematical Tools for ComputerGenerated Ornamental Patterns, Artistic Imaging and Digital Typography, Springer-Verlag Landon Ltd, pp. 193223.

[5] Kaplan C. S., 2002, Computer Graphics and Geometric Ornamental Design, Ph.D., University of Washington, Seattle.

[6] Aljamali A. M. and Banissi E., 2003, Grid Method Classification of Islamic Geometric Patterns, WSCG '2003 proceddings, February 3-7, 2003,

[7] Kaplan C. S., Bedi S., Mann S., Israeli G. and Poon G., 2004, A New Paradigm for Woodworking with NC
Machines, Computer Aided Design and Applications, Nos. 1-4, pp. 217-222.

[8] Djibril M., Hadi Y. and Oulad R. H. T., 2006, Fundamental Region Based Indexing and Classification of Islamic Star Pattern Images, Image Analysis and Recognisation, Springer Berlin/Heidelberg, Vol. 4142, pp. 865-876

[9] Grunbaum, B., 2006, Grid Method Classification of Islamic Geometric Patterns, AMS, Vol. 53, pp. 670-673.

[10] Djibril M., and Oulad R. H. T., 2008, Islamic Geometrical Patterns Indexing and Classification using Discrete Symmetry Groups, Journal on Computing and Cultural Heritage, Vol. 1, No. 2, Article 10.

[11] Ilkturk U., 2008, An Attempt to Combine Mathematics and Visual Arts, Master Thesis No. 087., University of Göteborg, Göteborg, Sweden.

[12] Jowers I., Prats M., Eissa H. and Lee J. H., 2010, A Study of Emergence in the generation of Islamic Star Patterns, International Conference on Computer-Aided Architectural Design Research, Asia CAADRIA 2010, pp. 39-48. 